\title{
Measuring serum human epididymis secretory protein autoantibody as an early biomarker of lung cancer
}

\author{
Bin Yang, Na Ren, Bo Guo, Hua Xin, Yiyu Yin \\ Department of Thoracic Surgery, China-Japan Union Hospital of Jilin University, Changchun 130000, China \\ Contributions: (I) Conception and design: Y Yin; (II) Administrative support: Y Yin; (III) Provision of study materials or patients: Y Yin, N Ren, \\ B Yang; (IV) Collection and assembly of data: Y Yin, N Ren, B Yang, B Guo; (V) Data analysis and interpretation: Y Yin, N Ren, H Xin; (VI) \\ Manuscript writing: All authors; (VII) Final approval of manuscript: All authors. \\ Correspondence to: Yiyu Yin. Department of Thoracic Surgery, China-Japan Union Hospital of Jilin University, 126 Xiantai Street, Changchun 130000, \\ China. Email: adamy00@163.com.
}

\begin{abstract}
Background: Lung cancer (LC) is one of the most common types of malignant tumors and is the most prominent cause of tumor-related death worldwide. LC is a heterogeneous disease caused by somatic cell mutations and dysregulation in several signaling pathways. Understanding these pathways provides the basis for detecting LC. LC screening and diagnosis in current clinic still rely on computed tomography (CT), but its high false positive rates and cost may prevent it from being a routine screening method. Therefore, the discovery of new non-invasive and more valuable biomarkers may present an improved diagnostic approach for LC, and potentially provide more useful information for the prognosis and treatment of LC in patients. This study investigated the potential of detecting serum autoantibodies produced against human epididymis secretory protein 4 (HE4) for LC diagnosis in high-risk groups.
\end{abstract}

Methods: Serum samples from 61 patients with LC were included in this study, and another 53 serum samples from healthy donors or benign lung diseases (BLD) patients were collected as the control group. The samples were analyzed with enzyme-linked immunosorbent assays (ELISA).

Results: ELISA results showed significantly higher levels of serum autoantibodies against HE4 in samples from LC patients compared to the control group $(\mathrm{P}<0.001)$. Analysis of HE4 autoantibodies showed a receiver operating characteristic (ROC) curve indicating $67.21 \%$ sensitivity, $96.23 \%$ specificity, and an area under the curve (AUC) of 0.848. Levels of HE4 autoantibodies can discriminate early-stage LC patients from the control group with a $54.76 \%$ sensitivity.

Conclusions: Detecting serum HE4 autoantibody levels may be a potential biomarker in high-risk groups of LC. We present a new method for the diagnosis of LC in the clinic.

Keywords: Tumor-associated antibodies (TAAbs); biomarker; lung cancer (LC); diagnosis

Submitted Sep 09, 2019. Accepted for publication Nov 22, 2019.

doi: $10.21037 /$ tcr.2019.11.50

View this article at: http://dx.doi.org/10.21037/tcr.2019.11.50

\section{Introduction}

Lung cancer (LC) is one of the most common types of malignant tumors and is the most prominent cause of tumor-related death worldwide. According to a report from the International Agency for Research on Cancer's report in 2018 (GLOBOCAN 2018), there are approximately 2.1 million cases of LC globally, accounting for $11.6 \%$ of all malignant tumors. Additionally, 1.8 million LC deaths were reported, accounting for $18.4 \%$ of all malignant tumors (1). There are two main types of LC: small cell LC (SCLC) and non-small cell LC (NSCLC). NSCLC accounts for about $80-90 \%$ of LC, consisting of adenocarcinoma (ADC), squamous cell carcinoma (SCC), and large cell carcinoma (LCC) $(2,3)$. In most cases, LC is not caused by point mutations, but is caused by a combination of multiple molecular changes leads to its formation. LC is a 
heterogeneous diseases caused by somatic cell mutations and dysregulation of multiple signaling pathways. Mutations in genes such as $\mathrm{p} 53$, p16, and $\mathrm{Rb}$ results in aberrant function of receptor tyrosine kinases (RTK), such as epidermal growth factor receptor (EGFR), and insulin-like growth factor 1 (IGF-1R) (4). Understanding these pathways provides a molecular basis for detecting LC. Current methods for screening and diagnosis in the clinic still rely on computed tomography (CT), but its high false positive rates and cost may prevent it from being a routine screening method (5-7). Therefore, the discovery of new non-invasive and more valuable biomarkers can present an improved diagnostic approach for LC, and potentially provide more useful information for the prognosis and treatment of LC patients in clinic.

Human epididymis secretory protein 4 (HE4), an oncogene, was firstly found in distal human epididymis epithelium cells in 1991 by Kirechhoff et al. (8), located on chromosome 20q 12-13.1, this gene which encodes a small molecular protein associated with sperm maturation belonging to the WAP four-disulfide core domain (WFDC) family (9). HE4 is mainly expressed in reproductive system cells, such as in ovaries, mammary gland epithelium, epididymis and vas deferens epithelium. However, it is also found in human respiratory tract and lungs $(10,11)$. HE4 is involved in the natural immune process in the respiratory tract, and in the mouth and nasal cavity, and may be related to the lung ADC (12). In addition, several studies have shown that elevated serum HE4 levels may be associated with ovarian cancer, and that detection of $\mathrm{HE} 4$ can even be used as a marker for early ovarian cancer $(13,14)$. Moore et al. found that detection of serum HE4 is more specific in early ovarian cancer screening compared with conventional carbohydrate antigen-125 (CA-125) (15). HE4 is overexpressed in most lung ADCs and in many lung SCCs, therefore, HE4 is an attractive target for LC diagnosis and prognosis of LC (12). Other relevant studies have also showed that serum $\mathrm{HE} 4$ can be used as a potential diagnostic marker for NSCLC (16-18). HE4 is a tumor-associated antigens (TAAs), which originates from tumor cells and are typically over-expressed, misfolded or abnormally degraded in patients with malignant tumors (19). Tumor-associated antibodies (TAAbs) are specifically produced in an immune response against TAAs, where detection of TAAbs can improve early diagnosis of malignant tumors with higher sensitivity and specificity than TAAs (20-22). In addition, serum TAAbs can still be detected by relevant technologies even if the concentration of TAAs in peripheral blood is very low and cannot be detected (23).

However, the feasibility of using TAAbs as biomarkers in LC remains unclear. The present study aims to evaluate the clinical significance of HE4 autoantibody expression in serums samples from LC patients.

\section{Methods}

\section{Patients}

A total of 61 serum samples from patients with LC referred to the China-Japan Union Hospital of Jilin University between May 2019 and July 2019 were included in this study. Serum samples were collected before the patients underwent LC surgery. Clinical characteristics from the patients are summarized in Table 1. All LC patients were confirmed by pathological examination.

\section{Controls}

A total of 24 serum samples were collected from patients with benign lung diseases (BLD) (infectious diseases, chronic obstructive pulmonary diseases and tuberculosis). Serum sample from 29 healthy donors were also collected. In contrast with patients from the LC group, control group donors have similar age and sex ration than patients in the LC group. The study was approved by the ethics committee of the China-Japan Union Hospital of Jilin University (approval number 2019071610). Informed consent was obtained from the participants in the study.

\section{Laboratory methods}

A blood sample was collected and serum was separated and stored at $-80{ }^{\circ} \mathrm{C}$ until tested. One hundred $\mu \mathrm{L}$ of $1 \mu \mathrm{g} / \mathrm{L}$ diluted human recombinant protein of HE4 (12609-H08H, Sino Biological Inc., Beijing, China) was adsorbed to 96-well plates, covered and incubated overnight at $4{ }^{\circ} \mathrm{C}$. After the recombinant protein coated plate was washed three times with PBS, subsequent to block with PBS containing 5\% bovine serum albumin (BSA). After washing, $100 \mu \mathrm{L}$ serum sample diluted 1:200 in PBS containing $0.5 \%$ BSA was added to each well, meanwhile, $100 \mu \mathrm{L}$ blocking buffer and rabbit anti-human HE4 monoclonal antibody (12609-R109, Sino Biological Inc., Beijing, China) diluted 1:10000 was also added to the negative and positive control wells, each sample was tested in duplicate. Following $2 \mathrm{~h}$ incubation at $37^{\circ} \mathrm{C}$, the plate was washed three times and $100 \mu l$ goat 
Table 1 Characteristics of samples

\begin{tabular}{|c|c|c|c|}
\hline Characteristics & $\begin{array}{l}\text { Patients } \\
(\mathrm{N}=61)\end{array}$ & $\begin{array}{l}\text { Controls } \\
(\mathrm{N}=53)\end{array}$ & $P$ value \\
\hline Male rate, $\mathrm{n}(\%)$ & $20(32.79 \%)$ & $19(35.85 \%)$ & $0.731^{a}$ \\
\hline Median age, years [range] & $\begin{array}{c}54.84 \pm 7.67 \\
{[44-70]}\end{array}$ & $\begin{array}{c}55.17 \pm 6.00 \\
{[44-60]}\end{array}$ & $0.075^{\mathrm{b}}$ \\
\hline \multicolumn{4}{|l|}{ Smoking history, n (\%) } \\
\hline$\leq 20$ years & $44(72.13)$ & $38(71.70)$ & $0.959^{\mathrm{a}}$ \\
\hline$>20$ years & $17(22.87)$ & $15(28.30)$ & \\
\hline \multicolumn{4}{|l|}{ Weight loss (WL), n (\%) } \\
\hline$\leq 5 \%$ (body weight) & $41(67.21)$ & - & \\
\hline >5\% (body weight) & $20(32.79)$ & - & \\
\hline \multicolumn{4}{|l|}{$\begin{array}{l}\text { Performance status (PS), } n \\
(\%)\end{array}$} \\
\hline $0-1$ & $40(65.57)$ & - & \\
\hline $2-4$ & $21(34.43)$ & - & \\
\hline \multicolumn{4}{|l|}{ Tumor type, n (\%) } \\
\hline ADC & $44(72.13)$ & - & \\
\hline SCC & $15(24.59)$ & - & \\
\hline SCLC & $2(3.28)$ & - & \\
\hline \multicolumn{4}{|l|}{ Stage, n (\%) } \\
\hline I & $28(45.90)$ & - & \\
\hline ॥ & $14(22.95)$ & - & \\
\hline III & $16(26.23)$ & - & \\
\hline IV & $3(4.92)$ & - & \\
\hline
\end{tabular}

${ }^{\mathrm{a}}$, Pearson Chi-square test; ${ }^{\mathrm{b}}$, independent sample $t$-test.

anti-rabbit and goat anti-human secondary antibody labeled with horseradish peroxidase (HRP) (SSA018, SSA016, Sino Biological Inc, Beijing, China) diluted 1:20,000 in 0.5\% BSA was added to the each well and incubated at $37{ }^{\circ} \mathrm{C}$ for $2 \mathrm{~h}$. After washed five times, $100 \mu \mathrm{L}$ of tetramethylbenzidine (TMB) substrate solution (P0209, Beyotime Biotechnology Inc., Shanghai, China) was added. After incubating at room temperature in the dark for $15 \mathrm{~min}, 100 \mu \mathrm{L}$ stop solution was added, and the optical density (OD) was measured at $450 \mathrm{~nm}$ with a reference wavelength of $620 \mathrm{~nm}$ in an ELISA plate reader.

\section{Statistical analysis}

SPSS 25.0 software was used for statistical analysis.
$T$-test was used for the age difference between groups, gender and smoking history was represented by rate or constituent ratio, Chi-square test was used to compare the difference between groups. The measured OD values of the two groups of serum samples were taken as the mean value of the duplicate wells. The statistical OD values were expressed as mean \pm standard deviation $(\bar{\chi} \pm \mathbf{s})$. Because the sample data did not have a normal distribution, the comparison of data between groups was performed using medians, and the nonparametric Mann-Whitney $U$ test was used to compare the difference between groups. The mean of the OD values of control group plus two standard deviations $(\bar{\chi} \pm \mathrm{s})$ was used as the cut-off value. A receiver operating characteristic (ROC) curve was used to compare the diagnostic value of the anti-HE4 autoantibody, and $\mathrm{P}<0.05$ was considered to indicate a statistically significant result.

\section{Results}

\section{HE4 autoantibody levels detection in the serum from $L C$ patients}

Serum levels of autoantibody to HE4 were significantly higher in patients with LC $(0.487 \pm 0.248)$ than control subjects $(0.208 \pm 0.098)(\mathrm{Z}=6.389, \mathrm{P}<0.001)$. A significant change was observed in the BLD group $(0.247 \pm 0.124)$ compared to heathy donors group $(0.175 \pm 0.056)(Z=-2.314$, $\mathrm{P}=0.021)$. Patients with either SCC or ADC had increased levels of HE4 autoantibodies. OD values in samples from ADC patients $(0.535 \pm 0.260)$ were significantly higher than in SCC patients $(0.336 \pm 154)(Z=-2.768, P=0.006)$ (Figure 1). However, performance status (PS) $(\mathrm{P}=0.390)$ and weight loss (WL) $(\mathrm{P}=0.261)$, showed that the levels of HE4 autoantibody levels were not significantly changed in the patient group, but were significantly different between clinical stages $(\mathrm{P}=0.022)$ (Figure 2).

\section{Diagnostic value of serum HE4 autoantibody in LC}

According to the cut-off value of 0.403 , serum HE4 autoantibody sensitivity was $67.21 \%$, the specificity was $96.23 \%$ and the Youden index was 0.648 (Table 2). Sensitivity of detecting serum HE4 autoantibody in an early stages of LC was $54.76 \%$ with 23 positive samples in earlystage LC groups. Evaluation of HE4 autoantibodies in LC by ROC curve analysis showed an AUC value of 0.848 (95\% CI: 0.776-0.920) (Figure 3). 

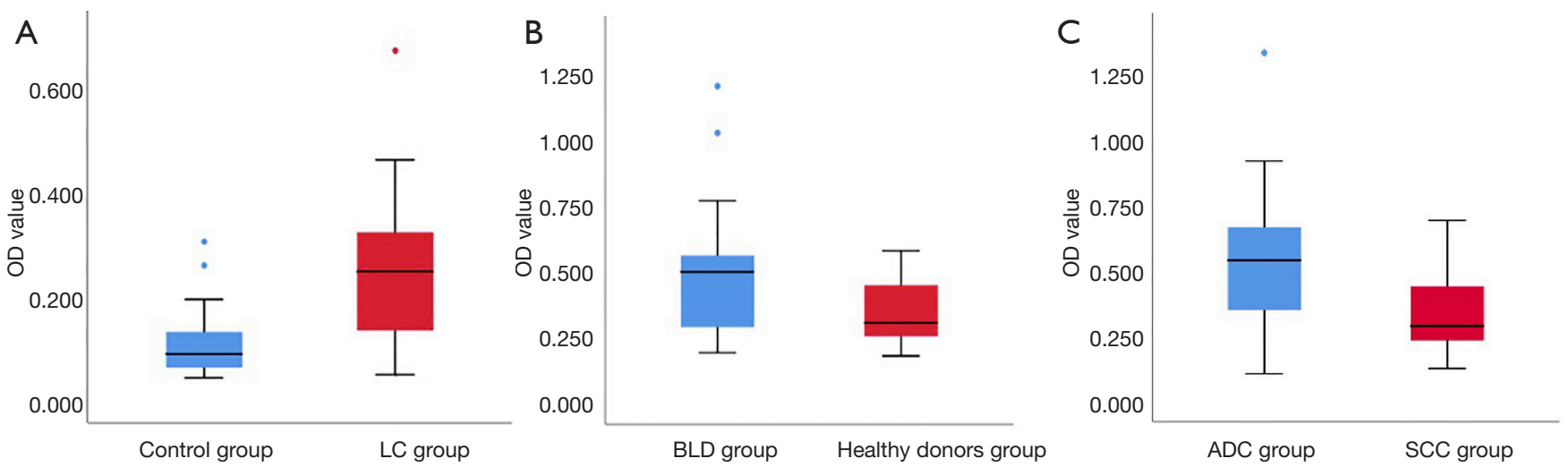

Figure 1 Serum levels of autoantibody to HE4 in different groups. (A) The serum levels of autoantibody to HE4 were significantly higher in patients with $\mathrm{LC}$ than control subjects $(\mathrm{P}<0.001)$. (B) The serum levels of autoantibody to HE4 were significantly higher in BLD patients than healthy donors $(\mathrm{P}=0.021)$. (C) The serum levels of autoantibody to HE4 were significantly higher in ADC patients than SCC patients $(\mathrm{P}=0.006)$. LC, lung cancer; BLD, benign lung disease; ADC, adenocarcinoma; SCC, squamous cell carcinoma.
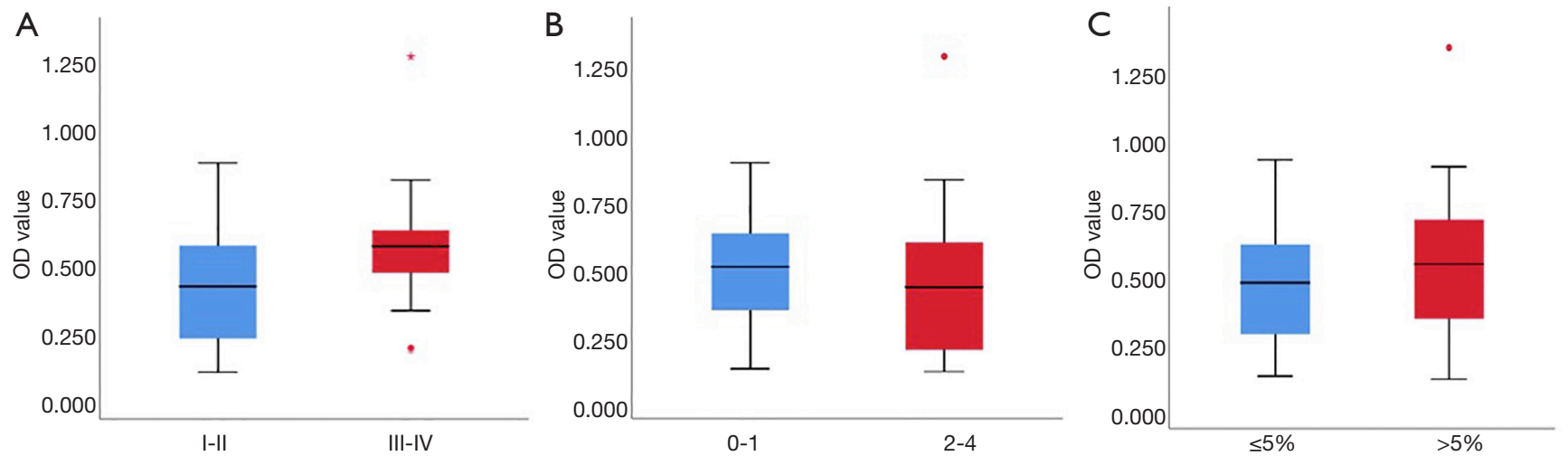

Figure 2 Serum levels of autoantibody to HE4 in different subgroups of LC patients. (A) The serum levels of autoantibody to HE4 were significantly higher in patients at III-IV stage than I-II stage (P=0.022). (B) The serum levels of autoantibody to HE4 were not significantly changed in patients with PS $0-1$ and 2-4 (P=0.390). (C) The serum levels of autoantibody to HE4 were not significantly changed in patients with $\mathrm{WL} \leq 5 \%$ and $\mathrm{WL}>5 \%(\mathrm{P}=0.261)$. WL, weight loss.

Table 2 The positive rate of serum HE4 autoantibody in two groups

\begin{tabular}{lcccl}
\hline Groups & $\begin{array}{c}\text { Positive rate } \\
(\%)\end{array}$ & $\begin{array}{c}\text { Sensitivity } \\
(\%)\end{array}$ & $\begin{array}{c}\text { Specificity } \\
(\%)\end{array}$ & P value \\
\hline LC $(\mathrm{N}=61)$ & $41(67.21)$ & 67.21 & 96.23 & $<0.001$ \\
Control $(\mathrm{N}=53)$ & $2(3.77)$ & & & \\
\hline
\end{tabular}

\section{Discussion}

Diagnostic methods for early LC detection by peripheral blood tests are preferred as they are more convenient and quicker Therefore, a series of tumor biomarkers, such as neuron-specific enolase (NSE) and carcino-embryonic antigen (CEA), are often used in the clinic, but detection sensitivities and specificities are not satisfactory. Tumorassociated autoantibodies (TAAbs) have been studied for many years, where certain TAAbs have potential diagnostic value (24-29). However, due to limitations such as sample quality and detection methods, further validation is required. The diagnostic value of the same TAAb varies between different studies. For example, sensitivity of detecting p55 autoantibodies was $12.6 \%$ in a German study (30), but was a reported $40.3 \%$ in a Japanese study (31). This may be related to the pathological subtypes of the 


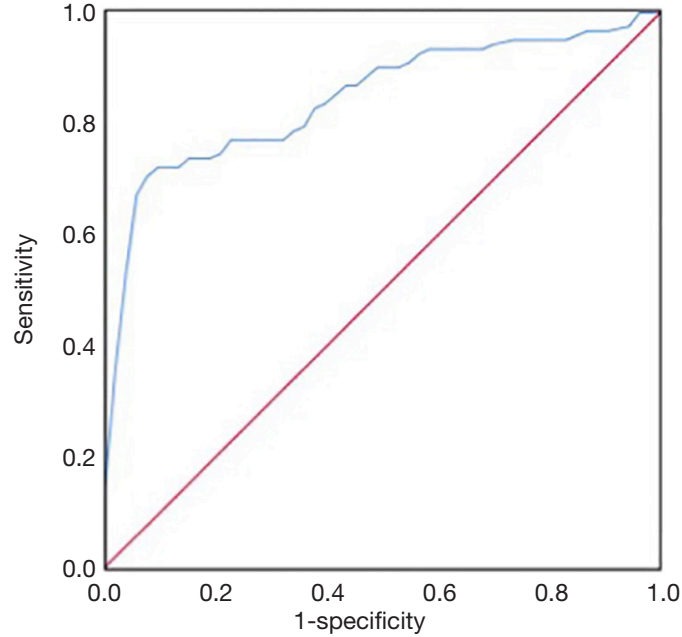

Figure 3 The sensitivity of serum HE4 autoantibody was $67.21 \%$, the specificity was $96.23 \%$. ROC curve analysis showed an AUC of 0.848 (95\% CI: 0.776-0.920) for HE4 autoantibody for LC. ROC, receiver operating characteristic; AUC, area under the curve; LC, lung cancer.

samples, since the former study mainly included the ADC and SCLC patients, while the latter study included a certain number of SCC patients. This suggested that $\mathrm{p} 53$ autoantibody levels may be higher in peripheral blood in SCC patients. Park et al. confirmed that the sensitivity of p53 autoantibody detection was $34.1 \%$ in patients with SCC (32). Therefore, in order to avoid such bias, ADC and SCC patients were both included in this study.

Although many TAAbs have been used for early diagnosis and prognosis in LC, they still can not be used in clinic due to their low sensitivities and specificities. Therefore, discovery of new TAAbs with high sensitivity and specificity is necessary. In this study, HE4 autoantibodies were studied to find its diagnostic potential for LC. Although detection of HE4 autoantibodies have been proved to have satisfactory diagnostic value in ovarian and breast cancers (15), there are no studies evaluating its use for LC. Therefore, the results of this study may provide supporting information for other TAAbs that are being researched for LC.

In this study serum samples from $61 \mathrm{LC}$ patients were detected by ELISA, including 44 cases of ADC, 15 cases of SCC and 2 cases of SCLC, serum levels of HE4 autoantibodies in 24 cases of BLD patients and 29 healthy donors were also detected. HE4 autoantibody levels in patients with LC group was significantly higher than in the BLD group and healthy donors group $(\mathrm{P}<0.001)$,
In addition, HE4 autoantibody levels were significantly different $(\mathrm{P}=0.021)$ in the BLD group compared with the healthy donors group, this may be related to the increase in HE4 levels in inflammatory tissues (33). Therefore, detection of HE4 autoantibody levels can be used to detect LC in high risk populations, and to distinguish between BLD patients and healthy people. Analysis of different LC pathology subtypes showed that serum levels of HE4 autoantibody in the ADC group was significantly higher than in SCC group ( $\mathrm{P}=0.006)$, which was consistent with results reported by Bingle et al. (12). Analysis of different clinical stages showed that serum HE4 autoantibody levels were significantly different $(\mathrm{P}=0.022)$, patients at more advanced stages had higher serum HE4 autoantibody levels than ones at early stages, which may because patients with advanced cancer have enhance the immune responses, where immune cells are constantly releasing autoantibodies. According to ROC curve analysis of serum HE4 autoantibody detection in LC diagnosis, sensitivity, specificity and AUC were $67.21 \%, 96.23 \%$, and 0.848 respectively. Hence, our results indicated that serum HE4 autoantibody has potential diagnostic value for LC. In addition, the detection sensitivity of serum HE4 autoantibody in early LC was $54.76 \%$, suggesting a potential test for early LC in clinic.

However, there are some limitations in this study. First, the sample size included was small, so there may be errors in representation. Second, healthy donors were not examined by bronchoscopy which may have generated errors in diagnosis. Third, ADC accounts for the majority of pathological subtypes in the LC group, so there may be some bias in comparing the ADC group to the SCC group. Fourth, ELISAs were the only detection method used in this study. Therefore, the value of serum HE4 autoantibodies for LC diagnosis still requires further validation, including a larger sample size and with samples from other centers.

\section{Conclusions}

In this study, we found that serum HE4 autoantibody is a potential biomarker for LC diagnosis. Additionally, we present a potential method for early LC screening in highrisk populations.

\section{Acknowledgments}

Funding: None. 


\section{Footnote}

Conflicts of Interest: The authors have completed the ICMJE uniform disclosure form (available at http://dx.doi. org/10.21037/tcr.2019.11.50). The authors have no conflicts of interest to declare.

Ethical Statement: The authors are accountable for all aspects of the work in ensuring that questions related to the accuracy or integrity of any part of the work are appropriately investigated and resolved. The study was conducted in accordance with the Declaration of Helsinki (as revised in 2013). The study was approved by the ethics committee of the China-Japan Union Hospital of Jilin University (approval number 2019071610). Informed consent was obtained from the participants in the study.

Open Access Statement: This is an Open Access article distributed in accordance with the Creative Commons Attribution-NonCommercial-NoDerivs 4.0 International License (CC BY-NC-ND 4.0), which permits the noncommercial replication and distribution of the article with the strict proviso that no changes or edits are made and the original work is properly cited (including links to both the formal publication through the relevant DOI and the license). See: https://creativecommons.org/licenses/by-nc$\mathrm{nd} / 4.0 /$.

\section{References}

1. Bray F, Ferlay J, Soerjomataram I, et al. Global Cancer Statistics 2018: GLOBOCAN Estimates of Incidence and Mortality Worldwide for 36 Cancers in 185 Countries. Ca Cancer J Clin 2018;68:394-424.

2. Berendsen HH, De Leij L, Poppema S, et al. Clinical characterization of non-small-cell lung cancer tumors showing neuroendocrine differentiation features. J Clin Oncol 1989;7:1614-20.

3. Sharma SV, Bell DW, Settleman J, et al. Epidermal growth factor receptor mutations in lung cancer. Nat Rev Cancer 2007;7:169-81.

4. Minna JD, Kasper DL, Braunwald E, et al. Harrison's Principles of Internal Medicine, 16th Edition online edition, 2007.

5. National Lung Screening Trial Research Team, Aberle DR, Adams AM, et al. Reduced lung-cancer mortality with low-dose computed tomographic screening. N Engl J Med 2011;365:395-409.
6. Croswell JM, Baker SG, Marcus PM, et al. Cumulative Incidence of False-Positive Test Results in Lung Cancer Screening: a randomized trial. Ann Intern Med 2010;152:505-12.

7. Tarro G, Perna A, Esposito C. Early diagnosis of lung cancer by detection of tumor liberated protein. J Cell Physiol 2005;203:1-5.

8. Kirechhoff C, Habben I, Ivell R, et al. A major human epididymis-specific cDNA encodes a protein with sequence homology to extracellular proteinase inhibitors. Biol Reprod 1991;45:350-7.

9. Bingle L, Singleton V, Bingle CD. The putative ovarian tumor marker gene HE4(WFDC2), is expressed in normal tissue and undergoes complex alternative splicing to yield multiple protein isoforms. Oncogene 2002;21:2768-73.

10. Galgano MT, Hampton GM, Frierson HF. Comprehensive analysis of HE4 expression in normal and malignant human tissues. Mod Pathol 2006;19:847-53.

11. Clauss A, Lilja H, Lundwall A. A locus on human chromosome 20 contains several genes expressing protease inhibitor domains with homology to whey acidic protein. Biochem J 2002;368:233-42.

12. Bingle L, Cross SS, High AS, et al. WFDC2 (HE4): a potential role in the innate immunity of the oral cavity and respiratory tract and the development of adenocarcinomas of the lung. Respir Res 2006;7:61.

13. Anastasi E, Marchei GG, Viggiani V, et al. HE4: a new potential early biomarker for the recurrence of ovarian cancer. Tumour Biol 2010;31:113-9.

14. Moore RG, Brown AK, Miller MC, et al. The use of multiple novel tumor biomarkers for the detection of ovarian carcinoma in patients with a pelvic mass. Gynecol Oncol 2008;108:402-8.

15. Moore RG, McMeekin DS, Brown AK, et al. A novel multiple marker bioassay utilizing HE4 and CA125 for the prediction of ovarian cancer in patients with a pelvic mass. Gynecol Oncol 2009;112:40-6.

16. Iwahori K, Suzuki H, Kishi Y, et al. Serum HE4 as a diagnostic and prognostic marker for lung cancer. Tumour Biol 2012;33:1141-9.

17. Yamashita S, Tokuishi K, Moroga T, et al. Serum level of HE4 is closely associated with pulmonary adenocarcinoma progression. Tumour Biol 2012;33:2365-70.

18. Jiang Y, Wang C, Lv B, et al. Expression level of serum human epididymis 4 and its prognostic significance in human non-small cell lung cancer. Int J Clin Exp Med 2014;7:5568-72.

19. Tan HT, Low J, Lim SG, et al. Serum autoantibodies 
as biomarkers for early cancer detection. FEBS J 2009;276:6880-904.

20. Leidinger P, Keller A, Ludwig N, et al. Toward an early diagnosis of lung cancer: an autoantibody signature for squamous cell lung carcinoma. Int J Cancer 2008;123:1631-6.

21. Wu L, Chang W, Zhao J, et al. Development of autoantibody signatures as novel diagnostic biomarkers of nonsmall cell lung cancer. Clin Cancer Res 2010;16:760-8.

22. Chapman CJ, Healey GF, Murray A, et al. EarlyCDT®Lung test: improved clinical utility through additional autoantibody assays. Tumour Biol 2012;33:1319-26.

23. Lu H, Goodell V, Disis ML. Humoral immunity directed against tumor-associated antigens as potential biomarkers for the early diagnosis of cancer. J Proteome Res 2008;7:1388-94.

24. Wang J, Zhang S, Ni W, et al. Development and application of a double- antibody sandwich ELISA kit for the detection of serum MUC1 in lung cancer patients. Cancer Biomark 2016;17:369-76.

25. Pedchenko T, Mernaugh R, Parekh D, et al. Early Detection of NSCLC with scFv Selected against IgM Autoantibody. PLoS One 2013;8:e60934.

26. Zhang Y, Ying X, Han S, et al. Autoantibodies against insulin-like growth factor-binding protein-2 as a

Cite this article as: Yang B, Ren N, Guo B, Xin H, Yin Y. Measuring serum human epididymis secretory protein autoantibody as an early biomarker of lung cancer. Transl Cancer Res 2020;9(2):735-741. doi: 10.21037/tcr.2019.11.50 serological biomarker in the diagnosis of lung cancer. Int J Oncol 2013;42:93-100.

27. Khattar NH, Coe-Atkinson SP, Stromberg AJ, et al. Lung cancer-associated auto-antibodies measured using seven amino acid peptides in a diagnostic blood test for lung cancer. Cancer Biol Ther 2010;10:267-72.

28. Yao X, Jiang H, Zhang C, et al. Dickkopf-1 autoantibody is a novel serological biomarker for non-small cell lung cancer. Biomarkers 2010;15:128-34.

29. Cherneva R, Petrov D, Georgiev O, et al. Clinical usefulness of alpha-crystallin antibodies in non-small cell lung cancer patients. Interact Cardiovasc Thorac Surg 2010;10:14-7.

30. Mack U, Ukena D, Montenarh M, et al. Serum anti-p53 antibodies in patients with lung cancer. Oncol Rep 2000;7:669-74.

31. Iizasa T, Fujisawa T, Saitoh Y, et al. Serum anti-p53 autoantibodies in primary resected non-small-cell lung carcinoma. Cancer Immunol Immunother 1998;46:345-9.

32. Park Y, Kim Y, Lee JH, et al. Usefulness of serum anti-p53 antibody assay for lung cancer diagnosis. Arch Pathol Lab Med 2011;135:1570-5.

33. Tang QF, Sun MZ, Zhou ZW, et al. Clinical study of 88 cases with increased HE4 expression. Guide of China Medicine 2017;15:85-6. 